\title{
The Use of Pre-heated Black Cumin Seeds (Nigella sativa) for Sorption Basic Dyes from Aqueous Solutions
}

\author{
Afrah Abood Hassan', Rawaa Al-Isawi ${ }^{1 *}$, Zahra Abd Saleh² \\ 1 Environmental Engineering Department, College of Engineering, University of Babylon, Babel, Iraq \\ 2 Civil Engineering Department, College of Engineering, University of Babylon, Babel, Iraq \\ * Corresponding author's e-mail: eng.rawaa.alisawi@uobabylon.edu.iq
}

\begin{abstract}
The discharge of industrial effluents containing dyes such as methylene blue (MB) and safranine T (ST) into water resources has caused serious problems for humans and organisms which live in water. On the other hand, the seeds of nigella sativa have been known to be effective and economical materials that present an excellent performance of dye removal from various types of wastewater. In this study, a different method from the existing literature was used, where the black cumin seeds (HBCS) were heated for a twenty-four hour period at $85{ }^{\circ} \mathrm{C}$ and ground to $300 \mu \mathrm{m}$ particle size to obtain new adsorbents for (MB) and (ST) dye adsorption from aqueous solutions. Four operating variables, which show a strong impact on adsorption, were tested by conducting a batch mode adsorption experiment and these were: the dye solution's initial $\mathrm{pH}(\mathrm{pH})$, the contact time $(\mathrm{t})$, the initial concentration of the dye $\left(\mathrm{C}_{0}\right)$, and the mass of the adsorbent $\left(\mathrm{m}_{a}\right)$. The sorption capacity of the adsorbent $(\mathrm{q})$ and the dye removal efficiency (\% Rem) were utilized as indicators of the impacts of selected operating variables on adsorption processes. It was found that the adsorption of MB and ST dyes increased when the initial concentration of the solution is higher. The adsorption of MB and ST dyes onto HBCS with initial concentration of $50 \mathrm{mg} / \mathrm{L}$ was $3.39 \mathrm{mg} / \mathrm{g}$ and $4.36 \mathrm{mg} / \mathrm{g}$, respectively. The equilibrium values for the MB and ST dyes corresponded with the Freundlich isotherm model onto HBCS highlighting the multi-layer adsorption process occurring which describes the interactions between the modified HBCS and the two dyes. The findings demonstrate that the optimum adsorption processes of the MB and ST dyes accrued in the 120 minutes and obtained at $\mathrm{pH}$ 10.7 and 11 for MB and ST, respectively. These conditions provide a negative charge for the surface of HBCS, causing its attraction to the positive charge of the MB and ST dyes. Kinetic studies elucidated that the MB and ST dyes adsorption onto HBCS most corresponded with pseudo-second order. The findings of this study could be implemented functionally in the industrial wastewater treatment sector.
\end{abstract}

Keywords: basic dye, kinetics, sorption, black cumin, equilibrium, Nigella sativa, isotherm model.

\section{INTRODUCTION}

The contamination of freshwater sources is presently regarded a worrying environmental issue to a modern-day world. Due to rapid industrial and unplanned urbanization activities and unskilled utilization of natural water resources, nearly $80 \%$ of the world population is facing the problems related to water security and fresh water supply degradation due to contamination [De Gisi et al., 2016]. The manufacturing industry is one of the major contributors to aquatic pollution to all over the world. Discharging the contaminated effluent to water resources causes a severe threat to the natural water system, human wellbeing and the whole ecosystem [Lellis et al., 2019]. The dyes in the effluent water from the textile, paper, pulp and dyeing industries should be removed before discarding the effluent into water systems [Tara et al., 2020]. It was reported that about " 5,000 10,000 " tons of dye are discharged into the water system every year [Benjelloun et al., 2021]. The dyes in water are detectably visible and can affect the color, taste and odor of the water. Many of these dyes have high levels of toxic and recalcitrant compounds, unmanageable organic 
pollutants, and even carcinogenic materials. This causes disastrous effects to aquatic and human life [Katheresan et al., 2018; Hynes et al., 2020].

Basic dyes are synthetic dyes that have a wide variety of industrial applications due to their concentrated color and easy application procedure [Bayomie et al., 2020; Benjelloun et al., 2021]. On the other hand, these dyes are characterized by their high solubility and poor biodegradation in water. It is estimated that about $(20-50) \%$ of them last in the outflow wastewater discharged from manufacturing industries into water bodies [Lellis et al., 2019]. Recently, as legislation has imposed strict requirements on the textile industrial effluent production, much consideration has been paid to treat the dye in the outflow wastewater. Hence, there is a high demand to remove, mineralize or transform the textile industry dyes from wastewater [Tara et al., 2020].

A scope of traditional remedying techniques for dye desegregation have been achieved broadly, including bio-electrochemical degradation, membrane filtration process, oxidation method, microbial technology, coagulation, photocatalytic degradation, and reverse osmosis [Katheresan et al., 2018; Shindhal et al., 2021]. In order to reduce the harmful consequences involved, adsorption has been considered an efficient technique for the removal of various types of dye from the aqueous solutions due to its easy application, low operational expenses, high tolerance to pollutant types, insusceptibility to toxins, capacity to treat different dyes from contaminated wastewater and the ability to regenerate the used adsorbent [AbdelGhani et al., 2019; Benjelloun et al., 2021]. Different adsorbents obtained from various materials were evaluated for their efficiency and efficacy in the elimination of dyes from aqueous solutions like; banana peel waste, biogenic selenium nanoparticles, natural zeolite, spent substrate of Pleurotus eryngii, pumice stone, natural clay, cellulosic olive stones and many others [Katheresan et al., 2018; Xia et al., 2018; Abukhadra and Mohamed, 2019; Soleimani et al., 2019; Al-Ghouti and Al-Absi, 2020; Tara et al., 2020; Maia et al., 2021; Paredes-Quevedo et al., 2021].

Application of the Nigella sativa seeds, often called black cumin, in treating wastewater has revealed many possibilities as a biosorbent [Qurratulane and Bhardwaj, 2014; Rahman et al., 2015]; therefore, studies have been conducted for its utility in the removal of various dyes from wastewater [Rakass et al., 2018; Abdel-Ghani et al., 2019;
Siddiqui et al., 2019; Thabede et al., 2020]. Nigella sativa is a perennial flowering herb plant, belonging to the round headed family (native to Eastern Europe and western Asia), characterized by its black small seeds and a distinctive taste and aromatic odor. Ripe seeds are consumed for medical and edible purposes [Srinivasan, 2018].

For the purpose of the present study, MB and ST, being described as concerning pollutants by various health organizations, were chosen as model materials to assess the efficiency of nigella sativa for eliminating the dyes from aqueous solutions. Generally, MB and ST are characterized by their high color intensity, even when in small amounts, and their complex structure makes them highly toxic [Siddiqui et al., 2018]. MB, usually recognized as basic blue 9 , is a stain or positivelycharged soluble dye that presents in the structure of a crystalline solid or a blue/green colored powder that separates in aqueous solutions as cations and chloride ions. General names of MB are Aizen methylene blue, methylthionine chloride, and Chromosmon [Al-Ghouti and Al-Absi, 2020].

$\mathrm{ST}$ is a basic red dye substance (basic red 2(BR-2) with an IUPAC designation as 3, 7-Diamino -2, 8-dimethyl-5-phenyl phenazinium chlorate and is a cationic dye [Xia et al., 2018]. It is used in different areas such as chemistry, biology, and medicine. ST, brown reddish powder, is aphenazine dye which is soluble in water and is primarily used as edible dye in coloring and flavoring cookies and candy. It is also utilized to color tannin, cotton, silk, bast fibers, leather, wool, and paper [Abukhadra and Mohamed, 2019]. In spite of the beneficial applications of MB and ST in science, these dyes have detrimental impacts on the environment and human life. They are highly water soluble, toxic and mutagenic agents, which have been shown to be carcinogenic [Thabede et al., 2020].

Although many studies have dealt with using the black cumin seeds as an effective adsorptive material in treating wastewater, in this study, the efficiency of modified nigella sativa (pre-heated black cumin seeds (HBCS)) adsorbents to eliminate basic dyes (MB and ST) from aqueous solutions was presented. In the literature, the adsorption studies using HBCS to treat MB and ST from aqueous solutions have not been reported to date. Different experimental factors including solution $\mathrm{pH}$, contact period, concentration of dye, and plant dosage were selected to perform the adsorption experiment. 


\section{MATERIALS AND METHODS}

\section{Preparation of adsorbents}

In this study, nigella sativa seeds (black cumin, also known as black caraway, nigella, kalojeera, kalonji or kalanji) were used as an adsorbent. The selection of black cumin seeds as absorbent in this study was due to their: low cost, availability in nature, low environmental impact, accessibility, lack of selection towards contaminants, easy reproduction, reusability, and the potential of their surface to have numerous efficient groups (carboxyl, hydroxyl and amide) [Srinivasan, 2018]. Such features set the black cumin plant in a beneficial place for adsorption technology.

The seeds of black cumin (BCS) were obtained from a wellness store in Babel Center, Babel, Iraq. The (BCS) were cleaned using distilled water before being used as an adsorbent to eliminate dirt. Later, the seeds were modified by heating to evaluate the impact of such condition on the removal of basic dyes. They were dried and heated in the oven for twenty-four hours at $85{ }^{\circ} \mathrm{C}$. Then, the heated black cumin seeds (HBCS) were ground to 300 $\mu \mathrm{m}$ particle size, labeled and stored at a temperature of $25{ }^{\circ} \mathrm{C}$ in covered glass containers that were cleaned with distilled water and purified to remove any contaminants, in preparation for the sorption process.

\section{Preparation of dye solutions}

Basic dyes (MB and ST) were utilized in this study as adsorbates. MBis a standard powder and has the molecular format $\mathrm{C}_{16} \mathrm{H}_{18} \mathrm{~N}_{3} \mathrm{SCl}$ (molecular weight: $319.86 \mathrm{~g} / \mathrm{mol}$ ) with CI Categorization Numeral 52015. MB is a basic blue tempera of spectroscopic rung and has a watery dissolvability of $50 \mathrm{~g} \mathrm{~L}^{-1}$ at $20^{\circ} \mathrm{C}$. In turn, ST (basic red 2) is a standard powder and has the molecular format $\mathrm{C}_{20} \mathrm{H}_{19} \mathrm{~N}_{4} \mathrm{Cl}$ (molecular weight: $350.84 \mathrm{~g} / \mathrm{mol}$ ) with CI classification numeral 50240. The ST dye is soluble in water and alcohol, it is composed of 3,7-Diamino-2,8-dimethyl-5-phenyl phenazinium chlorate [Wu et al., 2019]. Both dyes were obtained from the marketplace: Babylon Lab Chemical Co., Ltd, Babel, Iraq.

Two stock solutions of $50 \mathrm{mg} / \mathrm{L}$ were made by mixing appropriate amounts $(0.05 \mathrm{~g})$ of dry powdered dye of $\mathrm{MB}$ and $\mathrm{ST}$ in $1 \mathrm{~L}$ of water which was cleaned by double-distillation. In order to make the working solutions, the stock solution and distillate water were mixed to reach the accurate working solution concentration. The experiment solution $\mathrm{pH}$ was set using dilute hydrochloric acid. The UV/VIS Spectrophotometer (PerkinElmer Lamda 25 UV/VIS) was utilized to find the concentrations of MB and ST in solution. The maximum wavelength of $\lambda_{\max }=665 \mathrm{~nm}$ for $\mathrm{MB}$ and $\lambda_{\max }=520 \mathrm{~nm}$ for ST were used to measure the dye absorbance concentration. The absorbance-concentration profile was found by plotting a linear calibration curve of absorbance vs. the dye concentration.

\section{Batch adsorption experiment}

Batch experiments were used to determine the adsorption measurement by using a known amount of the modified adsorbent dosage (0.5-2) $\mathrm{g}$ mixed with $100 \mathrm{ml}$ of a known concentration of each aqueous dye solutions (MB and ST) in a sequence of conical flasks with $250 \mathrm{ml}$ capacity. The adjustment of $\mathrm{pH}$ was conducted by diluting the solution with $\mathrm{HCl}$ or $\mathrm{NaOH}(0.1 \mathrm{~mol} / \mathrm{L})$ and then calculating the $\mathrm{pH}$ with aSCT-BEN-PH-1 pH meter (JJS, Dallas, TX, USA). The test adsorption experiments were performed in a temperature-monitored $\left( \pm 1^{\circ} \mathrm{C}\right)$ (Oxylab, Babel) water vibrator. The mix solution was agitated at a fixed temperature at $250 \mathrm{rpm}$ and $120 \mathrm{~min}$. For pre-established period of time, the bottles were centrifuged and the concentration of the residual dye in the mixture was analyzed, after equilibrium was reached, by measuring the supernatant absorbance at the wavelength that corresponds to the optimum sample absorbance using an UV/ VIS Spectrophotometer at $650 \mathrm{~nm}$ and $520 \mathrm{~nm}$ for $\mathrm{MB}$ and ST, respectively.

For each dye, the impact of four variables on the adsorption capacity of HBCS was examined and these variables were: the initial $\mathrm{pH}$ of the dye solution $(\mathrm{pH})$, contact time $(\mathrm{t})$, the initial dye concentration $\left(\mathrm{C}_{0}\right)$ and mass of adsorbent $\left(\mathrm{m}_{a}\right)$. The effect of contact time was investigated for each dye at different time durations, which were: 15 , $30,45,60,75,90,105$ and 120 min and with standard concentration of $50 \mathrm{mg} / \mathrm{L}$. Then, $100 \mathrm{~mL}$ of each dye was placed into lidded bottles consisting of $2.0 \mathrm{~g}$ of the adsorbent. For a time period of 120 min, the impact of MB and ST was investigated at different concentration of: 10, 20, 40, 50, 60, 80,90 and $100 \mathrm{mg} / \mathrm{L}$. In regards to the MB solution, $100 \mathrm{~mL}$ of standard solution $(50 \mathrm{mg} / \mathrm{L})$ was placed into lidded bottles consisting of $2.0 \mathrm{~g}$ of 
the adsorbent and was assessed at varying $\mathrm{pH}$ of: $3.8,5.9,7,8.3$ and 10 , to study the impact of $\mathrm{pH}$ on the solution. The same process was applied for the ST solution at varying $\mathrm{pH}$ of: 4, 5, 7.5, 9.5 and 11. A vibrator was applied for each variable $(\mathrm{pH}$, contact time, dye concentration, and absorbent dose) to reach equilibrium between the adsorbent and working standard solution at $250 \mathrm{rpm}$.

\section{Equilibrium adsorption quantity and its removal efficiency}

Under the adsorption kinetics and adsorption isotherm model, adsorption experiments were set up using various adsorbent doses. The impact of the four chosen variables on the adsorbed quantity $(q)$ of HBCS and the percentages of dye removal (\% Rem) with HBCS were investigated.

The amount of adsorbate adsorbed by HBCS expressed per unit mass, $q$, and dye removal efficiency, \% Rem, of adsorption are found by Eqs. (1) and (2), respectively:

$$
\begin{gathered}
q=V \cdot\left(\frac{C_{o}-C_{f}}{m_{a}}\right) \\
\% \operatorname{Rem}=100 \cdot\left(\frac{C_{o}-C_{f}}{C_{o}}\right)
\end{gathered}
$$

where: $q$ - quantity of dye adsorbed by the adsorbent $(\mathrm{mg} / \mathrm{g}) ; V$ - the volume of the dye solution (L); $C_{O}$ - initial dye concentration in contact with the adsorbent $(\mathrm{mg} / \mathrm{L}) ; C_{f}$ - the concentration of the dye after the batch adsorption work $(\mathrm{mg} / \mathrm{L})$; and $m_{a}$ - the adsorbent mass $(\mathrm{g})$.

\section{Kinetics models}

Finding the rate at which sorbate is removed from the solution in kinetic order is required to build up a suitable sorption treatment processes [Senthil Kumar et al., 2014]. The adsorption kinetics, therefore, represent the main principle in the sorption process analysis [Benjelloun et al., 2021]. In order to assess the adsorption kinetics, the pseudo first-order (Equation (3)) [Lagergren, 1898] and second-order kinetics (Equation (4)) [Ho and McKay, 1999] demonstrated below are commonly used:

$$
\ln \left(q_{e}-q_{t}\right)=\ln q_{e}-k_{1} t
$$

$$
\frac{t}{q_{t}}=\frac{1}{k_{2} q_{e}^{2}}+\frac{t}{q_{e}}
$$

where: $q_{e}, q_{t}-$ the adsorbent's adsorption capacities $(\mathrm{mg} / \mathrm{g})$ at equilibrium and at a specific time $(t)(\mathrm{min})$, respectively, $k_{1}$ is the first-order kinetic rate constant (1/ $\min )$ and $k_{2}$ is the second-order kinetic rate constant $[(\mathrm{g} / \mathrm{mg})(1 / \mathrm{min})]$.

\section{Adsorption isotherm model}

The obtained data from the isotherm experiments was used to assess the various adsorption isotherm models. Due to their precise descriptions, adsorption isotherms are vital when determining adsorption mechanisms. The Langmuir and Freundlich models were employed to determine the types of adsorption process and evaluate the adsorption isotherm of dyes onto the adsorbent [Benjelloun et al., 2021].

The Langmuir model is suitable for single molecule adsorption, demonstrating the adsorption mechanism on homogeneous surfaces, and monolayer adsorption processes. Equation (5) shows the linear Langmuir model [Langmuir, 1918]:

$$
\frac{C_{e}}{q_{e}}=\frac{1}{q_{\max } \cdot b}+\frac{C_{e}}{q_{\max }}
$$

The Freundlich model describes a practical explanation of the single element adsorption equilibrium, and can be employed in a wide variety of fields. The model assumes the process is heterogeneous, multilayer adsorption [Kocaman, 2020]. Equation (6) shows the Freundlich model [Freundlich, 1906]:

$$
\log q_{e}=\log K_{f}+\frac{1}{n} \log C_{e}
$$

where: $C_{e}$ - the equilibrium concentration of the dye solution $(\mathrm{mg} / \mathrm{L}) ; q_{\max }, q_{e}$ - the maximum monolayer and equilibrium adsorption quantity of dye per HBCS mass, $(\mathrm{mg} / \mathrm{g})$ respectively; $b$ - the Langmuir equilibrium constant associated with the affinity of a dye molecule to the adsorbent $(\mathrm{L} / \mathrm{mg}) ; K_{f}$ - the Freundlich constant $[(\mathrm{mg} / \mathrm{g})(\mathrm{L} / \mathrm{mg}) 1 / \mathrm{n}]$ relating to the adsorptive bond energy, and $1 / n$ the strength factor of the adsorption or the heterogeneity of the surface. 


\section{RESULTS AND DISCUSSION}

\section{Impact of $\mathrm{pH}$ on dye adsorption}

The $\mathrm{pH}$ of the solution is an essential controlling parameter during the adsorption experiment. This experiment investigated the impact of $\mathrm{pH}$ on the removal capacity of MB and ST dyes using HBCS with the various $\mathrm{pH}$ values and Figure 1 displays these results. The removal capacity of MB and ST dyes was higher when $\mathrm{pH}$ was increased and the maximum removed capacity of the dyes was obtained at the $\mathrm{pH}$ of 10.07 and 11 for the MB dye and ST dye, respectively (Figure 1).

Furthermore, the removal percentage results also show an increase in the removal efficiency of each dye when the $\mathrm{pH}$ was increased and the maximum percentage was $90.45 \%$ at $\mathrm{pH}$ of 10.07 for the MB dye and $96.28 \%$ at $\mathrm{pH}$ of 11 for the ST dye. High $\mathrm{pH}$ values caused the surface of the adsorbent (HCBS) to become increasingly negatively charged and increases the dye attraction to the active sites of the surface of the adsorbent, explaining the increased removal efficiency of both dyes when $\mathrm{pH}$ is increased. The removal efficiency of both dyes with the increase in the solution $\mathrm{pH}$ showed a trend that is elucidated by the fact that decreasing $\mathrm{pH}$ caused the adsorbent (HBCS) surface to become more positively charged, therefore reducing the attraction of the dye to the active sites of the adsorbent surface [Xia et al., 2018]. The removal of the MB and ST dyes can be impacted by the zero point charge $\mathrm{pH}\left(\mathrm{pH}_{\text {zero }}\right)$ of the adsorbent. Below $\mathrm{pH}_{\text {zero }}$, the surface of the adsorbent becomes more positively charged. Following the results presented by this experiment, the values of $\mathrm{pH} 10.07$ and 11, for the $\mathrm{MB}$ dye and ST respectively, were selected as best suitable $\mathrm{pH}$ values for additional studies.

\section{Impact of contact time on the adsorption process}

Figure 2 presents the impacts of contact time on the MB and ST dye adsorption onto HBCS. The removal capacities of both dyes showed a similar trend, where the phase of rapid initial adsorption had proceeded to a slower phase of adsorption, when a plateau was attained. The highest adsorption removal of MB (93\%) and ST (96\%) dyes by HBCS were observed at $120 \mathrm{~min}$. The changes in dye removal efficiencies were consistent with both dyes' change in capacity of adsorption. Thabede et al., 2020, also noted similarly on MB adsorption onto activated carbon powder. Due to the high presence of adsorption sites on HBCS that can be available to interact with the dye molecules of the solution, there is a rapid adsorption phase initially. The rate of adsorption showed a slower increase with time due to the number of the active sites decreasing. When the adsorption and desorption of the dyes reach an equilibrium state, the plateau is established. However, a distinguished difference could be noted on the adsorption capacities of MB $(1.83 \mathrm{mg} / \mathrm{g})$ and ST $(2.2 \mathrm{mg} / \mathrm{g})$ dyes. The difference in the ionic strength of dye molecules may be the cause of the higher removal capacity of the ST dye in comparison to the MB dye onto HBCS [Xia et al., 2018].

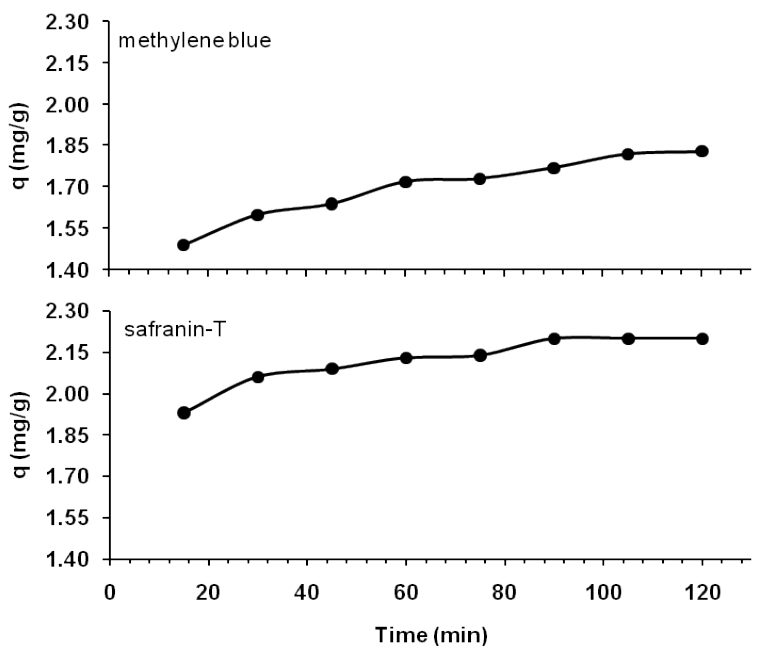

Figure 1. Impact of $\mathrm{pH}$ on the removed capacity of MB and ST dyes using $\operatorname{HBCS}\left(C_{0}=50 \mathrm{mg} / \mathrm{L}\right.$, $\mathrm{m}$ adsorbent $=2 \mathrm{~g}$, contact time $=120 \mathrm{~min}$ )

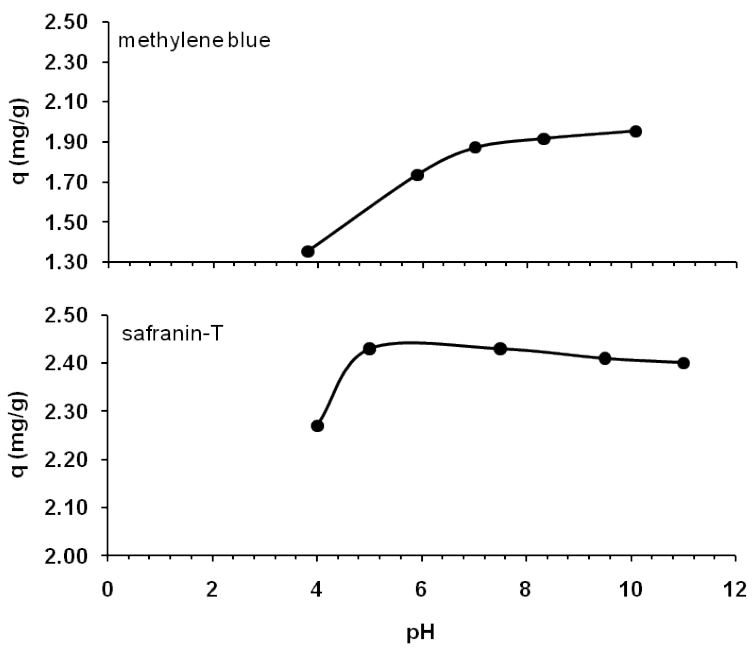

Figure 2. Impact of $\mathrm{pH}$ on the removed capacity of MB and ST dyes using HBCS 


\section{Impact of initial MB and ST dye concentrations}

Figure 3 shows the effects of initial dye concentration on the adsorption behavior of the MB and ST dyes by HBCS. The adsorption capacities of HCBS from $0.423 \mathrm{mg} / \mathrm{g}$ (at $10 \mathrm{mg} / \mathrm{L}$ ) to $3.39 \mathrm{mg} / \mathrm{g}$ (at 100 $\mathrm{mg} / \mathrm{L}$ ) for the MB dye and from $0.466 \mathrm{mg} / \mathrm{g}$ (at 10 $\mathrm{mg} / \mathrm{L}$ ) to $4.36 \mathrm{mg} / \mathrm{g}$ (at $100 \mathrm{mg} / \mathrm{L}$ ) for the ST dye can be noted. The change in the initial dye concentration is the same as the change in the total amount of dye molecules in the determined adsorbent mass and solution volume [Wong et al., 2020].

Therefore, higher adsorption capacity could be caused by more adsorbates binding to the active sites of the adsorbent due to increased concentration of dye molecules. This shows the high adsorption removal of MB (94.7\%) and ST (97.3\%) dyes at low dye concentrations $(10 \mathrm{mg} / \mathrm{L})$. At higher initial dye concentrations, it is expected that a higher number of adsorbates are in competition for the same amount of active sites which results in high adsorption sites saturation and the dye molecules become more distributed throughout the solution without absorption taking place. Consequently, the dye removal percentage of $67.95 \%(\mathrm{MB})$ and $87.3 \%(\mathrm{ST})$ is observed to decrease at the concentration of $100 \mathrm{mg} / \mathrm{L}$.

\section{Impact of the dose of adsorbent}

The impacts of the dose of adsorbent $\left(\mathrm{m}_{\mathrm{a}}\right)$ on $\mathrm{MB}$ and ST adsorption are shown in Figure 4. A notable reduction of adsorption capacity of HBCS can be observed from $6.17 \mathrm{mg} / \mathrm{g}$ (at $0.5 \mathrm{~g}$ a dose) to $1.99 \mathrm{mg} / \mathrm{g}$ (at a $2.0 \mathrm{~g}$ dose) for the MB dye, and from $7.26 \mathrm{mg} / \mathrm{g}$ (at a $0.5 \mathrm{~g}$ dose) to $2.0 \mathrm{mg} / \mathrm{g}$ (at a $2.0 \mathrm{~g}$ dose) for the ST dye. These results are comparable to the MB adsorption onto cellulosic olive stones biomass [Al-Ghouti and Al-Absi, 2020] and ST adsorption onto zeolite minerals [Abukhadra and Mohamed, 2019]. This trend is caused by the higher number of available active sites on HBCS at an increased dose of adsorbent and the number of molecules of adsorbate stays the same. Moreover, the inverse relationship between the dose of adsorbent and capacity of adsorption could also be the reason for the noticed trend as presented in Eq. (1).

\section{Sorption Kinetics assessment}

The kinetic estimation was conducted by applying the experiment results to the pseudo-firstorder (PFO) and pseudo-second-order (PSO) kinetic models, to assess the adsorption of MB onto HBCS. The linear coefficient of determination $\left(\mathrm{R}^{2}\right)$, kinetic rate constants $\left(\mathrm{k}_{1}\right.$ and $\left.\mathrm{k}_{2}\right)$ and the capacity of adsorption at equilibrium $\left(\mathrm{q}_{\mathrm{e}}\right)$ are presented in Table 1. The fitting plots at various initial $\mathrm{MB}$ dye concentrations are presented in Figures 5 (pseudo-first-order model) and 6 (pseudo-second-order model). It can be observed that the $\mathrm{R}^{2}$ values of the pseudo-firstorder kinetic model (Figure 5) were higher than those obtained by the pseudo-second-order (Figures 6) and the calculated $\left(\mathrm{q}_{\mathrm{e}}\right)$ results obtained from the second-order model were comparable with the experimental adsorption findings. The comparison of the $\mathrm{R}^{2}$ values pointed out that the adsorption values are more suitably fitted to the
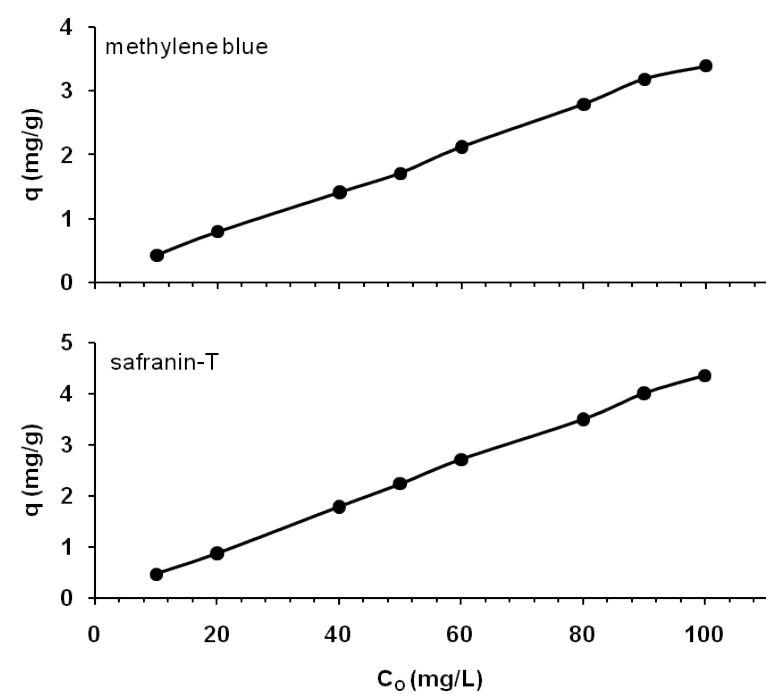

Figure 3. Impact of the dye's initial concentration on the removed capacity of MB and ST dyes using HBCS

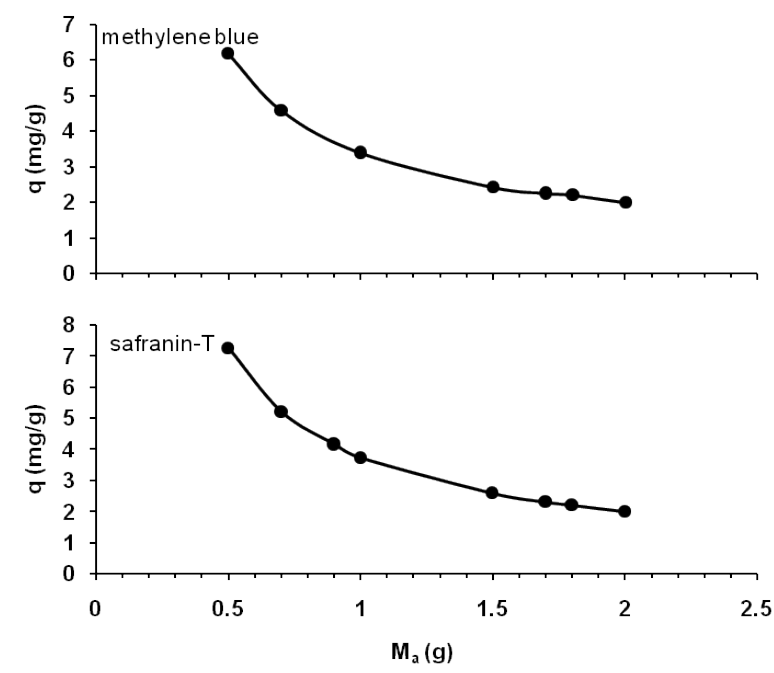

Figure 4. Impact of adsorbent dosage on the (MB) and (ST) adsorption onto HBCS 
PSO than the PFO model. These results display how HBCS adsorption kinetics of the MB dye fit the pseudo-second-order model and the adsorption of the MB dye onto HBCS is controlled by chemisorptions [Xia et al., 2018]. The process of adsorption in the pseudo-second-order model consists of three stages: the first one is the membrane diffusion stage, followed by the stage of

Table 1. The adsorption for kinetic variables when using HBCS to remove MB

\begin{tabular}{|c|c|c|c|c|c|c|c|c|}
\hline \multirow{2}{*}{$\begin{array}{c}\text { Conc. } \\
(\mathrm{mg} / \mathrm{l})\end{array}$} & \multirow{2}{*}{$\mathrm{q}_{\mathrm{e}}(\mathrm{mg} / \mathrm{g})$} & \multicolumn{3}{|c|}{$\mathrm{PFO}$} & \multicolumn{5}{c|}{$\begin{array}{c}\mathrm{q} \\
(\mathrm{q} / \mathrm{g})\end{array}$} & $\begin{array}{c}\mathrm{k}_{1} \\
(\mathrm{~g} / \mathrm{mg} \cdot \mathrm{min})\end{array}$ & $\mathrm{R}^{2}$ & $\begin{array}{c}\mathrm{q}_{\mathrm{e}} \\
(\mathrm{mg} / \mathrm{g})\end{array}$ & $\begin{array}{c}\mathrm{k}_{2} \\
(\mathrm{~g} / \mathrm{mg} \cdot \mathrm{min})\end{array}$ & $\begin{array}{c}\mathrm{h} \\
(\mathrm{mg} / \mathrm{g} \cdot \mathrm{min})\end{array}$ & $\mathrm{R}^{2}$ \\
\hline 10 & 0.436 & 0.455 & 0.048 & 0.755 & 0.459 & 0.262 & 0.055 & 0.995 \\
\hline 15 & 0.673 & 1.765 & 0.053 & 0.668 & 0.761 & 0.063 & 0.036 & 0.969 \\
\hline 20 & 0.832 & 1.065 & 0.058 & 0.864 & 0.884 & 0.147 & 0.114 & 0.998 \\
\hline 25 & 1.06 & 0.827 & 0.038 & 0.811 & 1.122 & 0.097 & 0.122 & 0.997 \\
\hline
\end{tabular}

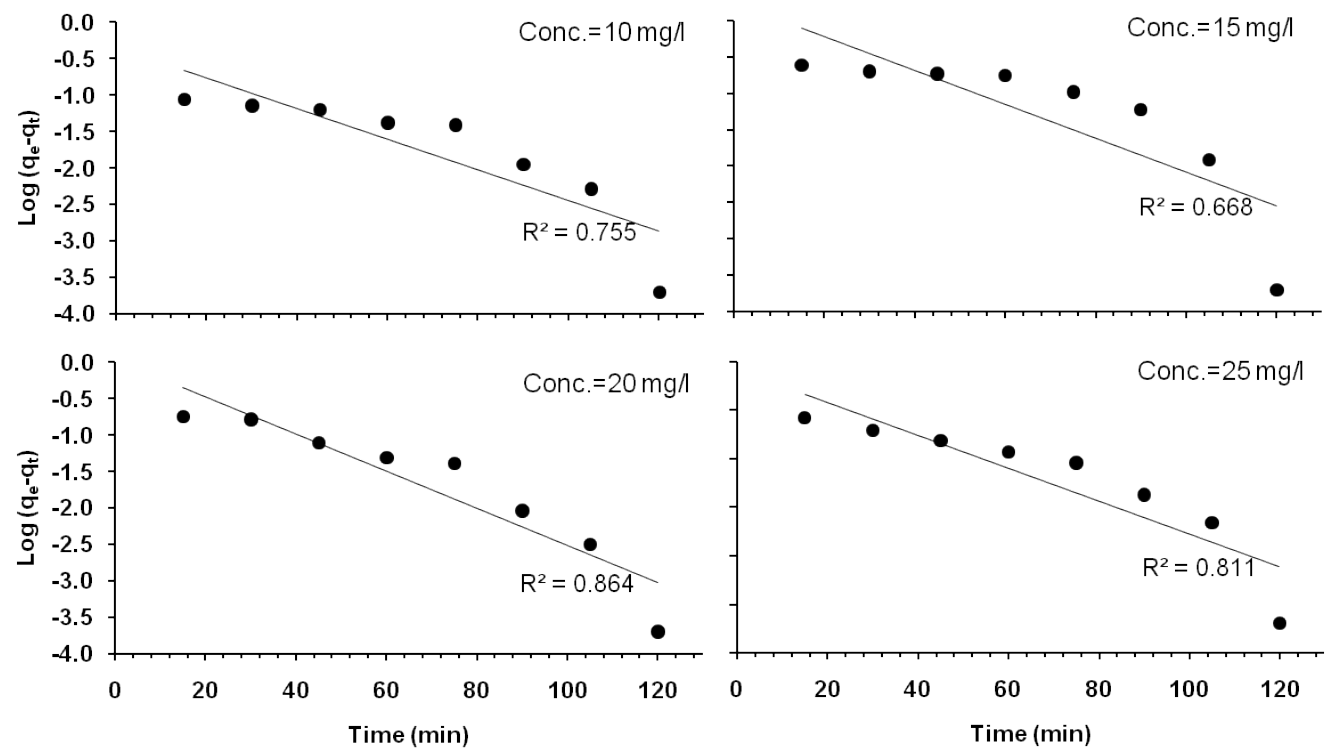

Figure 5. Pseudo-first order graphs for the impact of contact time and initial dye concentration on removal of MB using HBCS

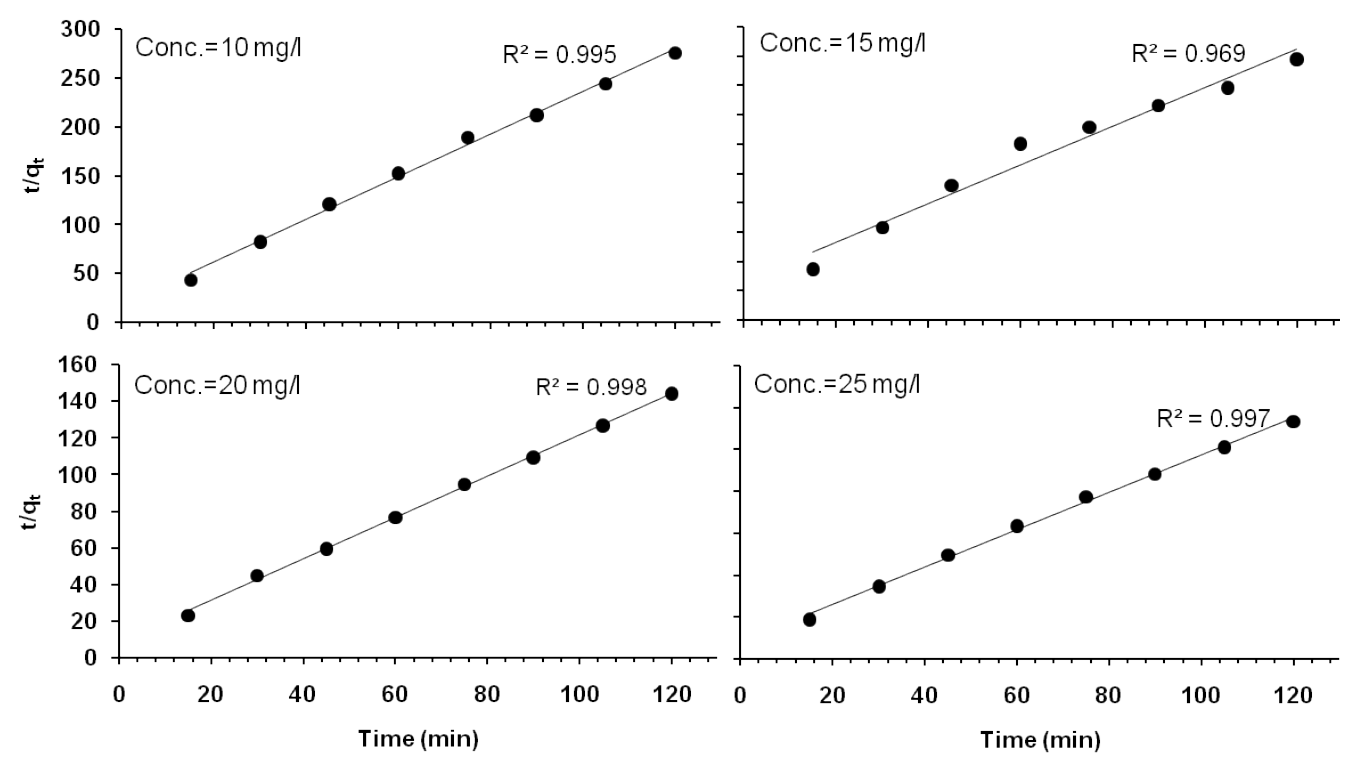

Figure 6. Pseudo-second order graphs for the impact of contact time and initial dye concentration on removal of MB using HBCS 
surface adsorption and finally, the internal diffusion process stage. This model demonstrates the existing adsorption process well [Kocaman, 2020], highlighting the complex process of the absorption of dyes by HBCS. Similar adsorption features were noted for the substrate of Pleurotus eryngii [Wu et al., 2019] and the levulinic acidmodified natural shells [Kocaman, 2020].

\section{Adsorption isotherm analysis}

The Langmuir and Freundlich isotherms were utilized to work out the maximum capacity of adsorption, demonstrating how the adsorbate and biosorbent interact and to find the solid-liquid interface adsorption. According to equations 5 and 6 , the adsorption values were applied to these two models in order to analyze the adsorption isotherm. The model adsorption isotherm variables and data of the coefficient of determination values $\left(\mathrm{R}^{2}\right)$ are presented in Table 2 as well as illustrated in Figures 7 (Langmuir isotherm) and 8 (Freundlich isotherms). The values of $\mathrm{R}^{2}$ coefficient of the Freundlich model were higher than those of the Langmuir model, which indicated that the Freundlich model is a better demonstration for the adsorption data of both dyes (Table 2). The sorption of MB and ST on the HBCS adsorbent followed the Freundlich isotherm model with $\mathrm{R}^{2}$ being 0.956 and 0.981 for the MB and ST dyes, respectively. Such results indicate the occurrence of multilayer adsorption with heterogeneous nature making an interaction between the adsorbate and the adsorbent, which was also observed in the MB adsorption onto activated carbon particles [Thabede et al., 2020]Fourier transformed infrared (FIR, as well as the ST adsorption onto the spent substrate of Pleurotus eryngii [Wu et al., 2019]. It was shown that the adsorption on the surface of the adsorbent was linear and uniform due to the fact that the Freundlich parameter (n) was established to be in the range of $0-1$ (Table 2). The Freundlich isotherm is one of the most fitted isotherms for demonstrating the process of adsorption occurring on heterogeneous surfaces which can be expressed by the heterogeneous nature of the preheated black cumin seeds.

\section{CONCLUSIONS}

The effectiveness of modified pre-heated black cumin seeds (HBCS) was evaluated for the removal of methylene blue (MB) and safranine T (ST) dyes from aqueous solution. A batch mode of adsorption experiment was conducted with variables of $\mathrm{pH}$, contact time, initial dye concentration, and adsorbent dosage. The results demonstrated that the $\mathrm{pH}$ of the solution influences the adsorption of $\mathrm{MB}$ and ST. It was noted that higher initial concentration of the solutions increased the adsorption capacity for the MB and ST dyes. The findings present that the maximum adsorption processes were noticed at

Table 2. MB and ST dye isotherm parameters for adsorption onto HBCS

\begin{tabular}{|c|c|c|c|c|c|c|}
\hline \multirow{2}{*}{ Dyes } & \multicolumn{3}{|c|}{ Langmuir } & \multicolumn{3}{c|}{ Freundlich } \\
\cline { 2 - 7 } & $\begin{array}{c}\mathrm{q}_{\max } \\
(\mathrm{mg} / \mathrm{g})\end{array}$ & $\begin{array}{c}\mathrm{b} \\
(\mathrm{L} / \mathrm{mg})\end{array}$ & $\mathrm{R}^{2}$ & $\mathrm{~K}_{\mathrm{f}}$ & $\mathrm{n}$ & $\mathrm{R}^{2}$ \\
\hline MB & -4.508 & -0.028 & 0.841 & 0.055 & 0.655 & 0.956 \\
\hline ST & -1.26 & -0.06 & 0.926 & 0.00043 & 0.270 & 0.981 \\
\hline
\end{tabular}

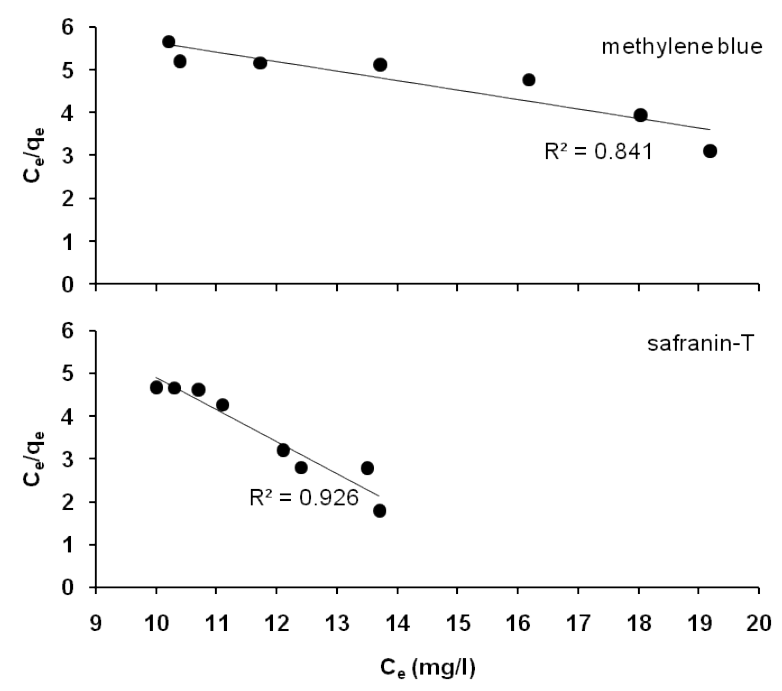

Figure 7. Graphs for Langmuir isotherm adsorption of $\mathrm{MB}$ and $\mathrm{ST}$ dyes

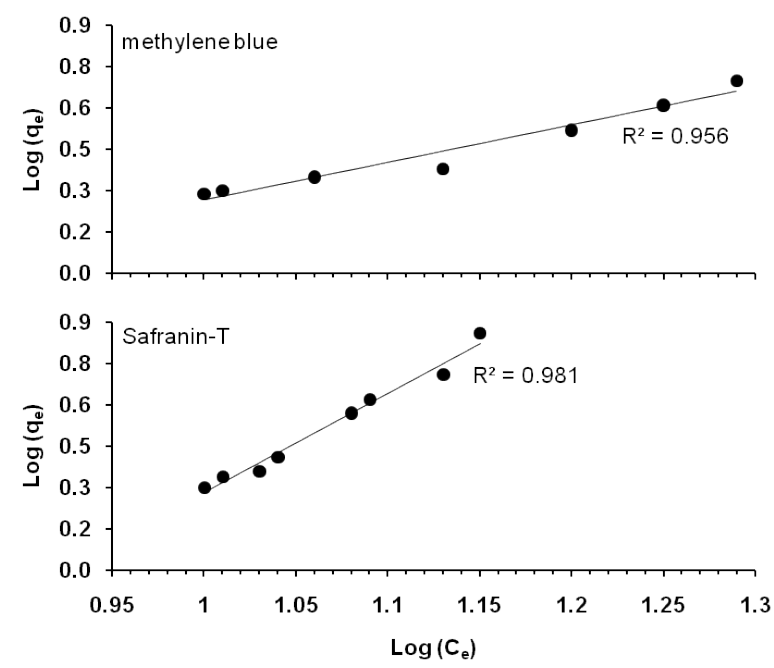

Figure 8. Graphs for Freundlich isotherm adsorption of MB and ST dyes 
120 min. The adsorption kinetics was demonstrated well by the pseudo-second order for the HBCS. Furthermore, the adsorption data was better fitted with the Freundlich isotherm model than with the Langmuir model that indicated the heterogeneous nature of adsorbent surfaces. The findings of this research show the functionality of modified HBCS adsorbent as an alternative for removing $\mathrm{MB}$ and ST dyes from aqueous solutions.

\section{Acknowledgements}

The author would like to acknowledge the laboratory technologists of the department of environmental engineering in the college of engineering at the University of Babylon for their support during the research period.

\section{REFERENCES}

1. Abdel-Ghani N.T., El-Chaghaby G.A., Rawash E.S.A., Lima E.C. 2019. Magnetic activated carbon nanocomposite from Nigella sativa L. waste (MNSA) for the removal of Coomassie brilliant blue dye from aqueous solution: Statistical design of experiments for optimization of the adsorption conditions. JAdv Res, 17, 55-63.

2. Abukhadra M.R., Mohamed A.S. 2019. Adsorption Removal of Safranin Dye Contaminants from Water Using Various Types of Natural Zeolite. Silicon, 11(3), 1635-1647.

3. Al-Ghouti M.A., Al-Absi R.S. 2020. Mechanistic understanding of the adsorption and thermodynamic aspects of cationic methylene blue dye onto cellulosic olive stones biomass from wastewater. Sci Rep, 10(1), 1-18.

4. Bayomie O.S., Kandeel H., Shoeib T., Yang H., Youssef N., El-Sayed M.M.H. 2020. Novel approach for effective removal of methylene blue dye from water using fava bean peel waste. Sci Rep, 10(1), 1-10.

5. Benjelloun M., Miyah Y., Akdemir Evrendilek G., Zerrouq F., Lairini S. 2021. Recent Advances in Adsorption Kinetic Models: Their Application to Dye Types. Arab J Chem, 14(4), 103031.

6. Freundlich H.M.F. 1906. Over the Adsorption in Solution. J Phys Chem, 57, 385-471.

7. Gisi S.D., Lofrano G., Grassi M., Notarnicola M. 2016. Characteristics and adsorption capacities of low-cost sorbents for wastewater treatment: A review. Sustain Mater Technol, 9, 10-40.

8. Ho Y., McKay G. 1999. Pseudo-second order model for sorption processes. Process Biochem, 34(5), 451-465.

9. Hynes N.R.J., Kumar J.S., Kamyab H., Sujana J.A.J., Al-Khashman O.A., Kuslu Y., Ene A., Suresh
Kumar B. 2020. Modern enabling techniques and adsorbents based dye removal with sustainability concerns in textile industrial sector -A comprehensive review. J Clean Prod, 272, 122636.

10. Katheresan V., Kansedo J., Lau S.Y. 2018. Efficiency of various recent wastewater dye removal methods: A review. J Environ Chem Eng, 6(4), 4676-4697.

11. Kocaman S. 2020. Removal of methylene blue dye from aqueous solutions by adsorption on levulinic acid-modified natural shells. Int J Phytoremediation, 22(8), 885-895.

12. Lagergren S. 1898. About the theory of so-called adsorption of soluble substances, Zur theorie der sogenannten adsorption gelster stoffe. K Sven Vetenskapsakademiens, Handl Band, 24, 1-39.

13. Langmuir I. 1918. The adsorption of gases on plane surfaces of glass, mica and platinum. J Am Chem Soc, 40(9), 1361-1403.

14. Lellis B., Fávaro-Polonio C.Z., Pamphile J.A., Polonio J.C. 2019. Effects of textile dyes on health and the environment and bioremediation potential of living organisms. Biotechnol Res Innov, 3(2), 275-290.

15. Maia L.S., Duizit L.D., Pinhatio F.R., Mulinari D.R. 2021. Valuation of banana peel waste for producing activated carbon via $\mathrm{NaOH}$ and pyrolysis for methylene blue removal. Carbon Lett, 31(4), 749-762.

16. Paredes-Quevedo L.C., González-Caicedo C., Torres-Luna J.A., Carriazo J.G. 2021. Removal of a Textile Azo-Dye (Basic Red 46) in Water by Efficient Adsorption on a Natural Clay. Water, Air, Soil Pollut, 232(1), 4.

17. Qurratulane B., Bhardwaj N. 2014. Role of BioSorbents in The Decolorization of Some Commonly Used Dyes. J Sci, 4(10), 637-642.

18. Rahman H.H.A., MoustafaA.H.E., Kassem M.G. 2015. Black cumin (Nigella sativa) as Low Cost Biosorbent For the Removal of Toxic $\mathrm{Cu}$ (II) and $\mathrm{Pb}$ (II) From Aqueous Solutions. Int J Eng Technol, 15(2), 46-66.

19. Rakass S., Mohmoud A., Hassani H.O., Abboudi M., Kooli F., Wadaani F.A. 2018. Modified nigella sativa seeds as a novel efficient natural adsorbent for removal of methylene blue dye. Molecules, 23(8).

20. Senthil Kumar P., Palaniyappan M., Priyadharshini M., Vignesh A.M., Thanjiappan A., Sebastina Anne Fernando P., Tanvir Ahmed R., Srinath R. 2014. Adsorption of basic dye onto raw and surface-modified agricultural waste. Environ Prog Sustain Energy, 33(1), 87-98.

21. Shindhal T., Rakholiya P., Varjani S., Pandey A., Ngo H.H., Guo W., Ng H.Y., Taherzadeh M.J. 2021. A critical review on advances in the practices and perspectives for the treatment of dye industry wastewater. Bioengineered, 12(1),70-87.

22. Siddiqui S.I., Rathi G., Chaudhry S.A. 2018. Qualitative analysis of acid washed black cumin seeds for 
decolorization of water through removal of highly intense dye methylene blue. Data Br, 20,1044-1047.

23. Siddiqui S.I., Zohra F., Chaudhry S.A. 2019. Nigella sativa seed based nanohybrid composite- $\mathrm{Fe}_{2} \mathrm{O}_{3}-$ $\mathrm{SnO}_{2} / \mathrm{BC}$ : A novel material for enhanced adsorptive removal of methylene blue from water. Environ Res, 178, 108667.

24. Soleimani H., Mahvi A.H., Yaghmaeian K., Abbasnia A., Sharafi K., Alimohammadi M., Zamanzadeh M. 2019. Effect of modification by five different acids on pumice stone as natural and low-cost adsorbent for removal of humic acid from aqueous solutions - Application of response surface methodology. J Mol Liq, 290, 111181.

25. Srinivasan K. 2018. Cumin (Cuminum cyminum) and black cumin (Nigella sativa) seeds: traditional uses, chemical constituents, and nutraceutical effects. Food Qual Saf, 2(1), 1-16.

26. Tara N., Siddiqui S.I., Rathi G., Chaudhry S.A., Inamuddin, Asiri A.M. 2020. Nano-engineered
Adsorbent for the Removal of Dyes from Water: A Review. Curr Anal Chem, 16(1), 14-40.

27. Thabede P.M., Shooto N.D., Naidoo E.B. 2020. Removal of methylene blue dye and lead ions from aqueous solution using activated carbon from black cumin seeds. South African J Chem Eng, 33(April), 39-50.

28. Wong S., Ghafar N.A., Ngadi N., Razmi F.A., Inuwa I.M., Mat R., Amin N.A.S. 2020. Effective removal of anionic textile dyes using adsorbent synthesized from coffee waste. Sci Rep, 10(1), 1-13.

29. Wu J., Xia A., Chen C., Feng L., Su X., Wang X. 2019. Adsorption Thermodynamics and Dynamics of Three Typical Dyes onto Bio-adsorbent Spent Substrate of Pleurotus eryngii. Int J Environ Res Public Health, 16(5), 679.

30. Xia X., Zhou Z., Wu S., Wang D., Zheng S., Wang G. 2018. Adsorption removal of multiple dyes using biogenic selenium nanoparticles from an escherichia coli strain overexpressed selenite reductase CsrF. Nanomaterials, 8(4), 1-15. 